\title{
Avaliação do Índice de Anomalia de Chuva para a região central do Estado do
}

\section{Espírito Santo}

\author{
Evaluation of the Rain Anomaly Index for the central region of the State of Espírito Santo \\ Evaluación del Índice de Anomalías de Lluvia para la región central del Estado de Espírito Santo
}

Recebido: 29/08/2021 | Revisado: 07/09/2021 | Aceito: 13/09/2021 | Publicado: 14/09/2021

\author{
Marcelo Henrique Fernandes de Faria Rocha \\ ORCID: https://orcid.org/0000-0001-6041-6233 \\ Universidade Vale do Rio Verde, Brasil \\ E-mail: mhffr@yahoo.com \\ Alisson Souza de Oliveira \\ ORCID: https://orcid.org/0000-0001-7885-9542 \\ Universidade Vale do Rio Verde, Brasil \\ E-mail: alissonso@hotmail.com \\ Gustavo Andrade Moreira \\ ORCID: https://orcid.org/0000-0002-0433-1304 \\ Universidade FUMEC, Brasil \\ gustavo.moreira@hybrazil.com \\ Karina de Jesus Soares \\ ORCID: https://orcid.org/0000-0002-0504-0082 \\ Universidade Estadual do Norte Fluminense, Brasil \\ E-mail: kjsoares.agro@gmail.com \\ Rosângela Francisca de Paula Vitor Marques \\ ORCID: https://orcid.org/0000-0001-6646-0809 \\ Universidade Vale do Rio Verde, Brasil \\ E-mail: roeflorestal@hotmail.com \\ Antonione Araújo Coelho \\ ORCID: https://orcid.org/0000-0002-5773-449X \\ Universidade Estadual do Norte Fluminense, Brasil \\ E-mail: aacoellho@gmail.com
}

\begin{abstract}
Resumo
Índices climáticos como o de Anomalia de Chuva (IAC) permitem o desenvolvimento de sistemas de monitoramento de períodos secos ou chuvosos e facilitam a comunicação de informações sobre anomalias climáticas para diversos setores da sociedade. Neste sentido, o objetivo deste trabalho foi avaliar o IAC da região central do Estado do Espírito Santo considerando a metodologia proposta por Rooy (1965) e adaptada por Freitas (2004) e Araújo (2009). O IAC das estações adotadas foi comparado com os parâmetros das Zonas Naturais do Espírito Santo (Espírito Santo, 1999). Adicionalmente, visando verificar os impactos que o clima global causa sobre a distribuição pluviométrica regional, foram consideradas eventuais influências de El Niño (EN) e La Niña (LN) sobre os valores de IAC obtidos. Os resultados indicam alterações nos padrões das chuvas da região, aparentes contradições em relação ao zoneamento natural do Espírito Santo e, por fim e não menos importante, notável variabilidade pluviométrica nos postos avaliados, circunstâncias que revelam ser imperiosa a realização de mais pesquisas climatológicas na região com enfoque na precipitação pluviométrica. O IAC médio da área de estudo aponta para o aumento da ocorrência de eventos severos, constatação particularmente importante tendo em vista as possíveis implicações negativas na cadeia socioeconômica da região bem como os desastres socioambientais potencialmente associados.
\end{abstract}

Palavras-chave: Climatologia; Precipitação pluviométrica; Índice de anomalia de chuva; Estiagem; Severidade climática.

\begin{abstract}
Climatic indices such as the Rain Anomaly (RAI) allow the development of monitoring systems for dry or rainy periods and facilitate the communication of information on climatic anomalies to different sectors of society. In this sense, the objective of this work was to evaluate the RAI of the central region of the State of Espírito Santo considering the methodology proposed by Rooy (1965) and adapted by Freitas (2004) and Araújo (2009). The RAI of the adopted stations was compared with the parameters of the Natural Zones of Espírito Santo (Espírito Santo, 1999). Additionally, in order to verify the impacts that the global climate causes on the regional rainfall distribution, possible influences of El Niño (EN) and La Niña (LN) on the obtained IAC values were considered. The results indicate changes in rainfall patterns in the region, apparent contradictions in relation to the natural zoning of Espírito Santo and, last but not least, remarkable rainfall variability in the evaluated stations, circumstances that reveal that it is
\end{abstract}


imperative to carry out more climatological research in the region focusing on rainfall. The average IAC in the study area points to an increase in the occurrence of severe events, a particularly important finding in view of the possible negative implications in the socioeconomic chain of the region, as well as the potentially associated socioenvironmental disasters.

Keywords: Climatology; Rainfall; Rain anomaly index; Drought; Climatic severity.

\section{Resumen}

Índices climáticos como el anomalía de lluvia (IAC) permiten el desarrollo de sistemas de monitoreo de períodos secos o lluviosos y facilitan la comunicación de información sobre anomalías climáticas a diferentes sectores de la sociedad. En este sentido, el objetivo de este trabajo fue evaluar el IAC de la región central del Estado de Espírito Santo considerando la metodología propuesta por Rooy (1965) y adaptada por Freitas (2004) y Araújo (2009). Se comparó el IAC de las estaciones adoptadas con los parámetros de las Zonas Naturales de Espírito Santo (Espírito Santo, 1999). Adicionalmente, para verificar los impactos que el clima global provoca en la distribución regional de las precipitaciones, se consideraron las posibles influencias de El Niño (EN) y La Niña (LN) en los valores de IAC obtenidos. Los resultados indican cambios en los patrones de precipitación en la región, aparentes contradicciones en relación a la zonificación natural de Espírito Santo y, por último pero no menos importante, notable variabilidad de lluvias en las estaciones evaluadas, circunstancias que revelan que es imperativo realizar más investigaciones climatológicas. en la región centrándose en las precipitaciones. El IAC promedio en el área de estudio apunta a un aumento en la ocurrencia de eventos severos, un hallazgo particularmente importante en vista de las posibles implicaciones negativas en la cadena socioeconómica de la región, así como los desastres socioambientales potencialmente asociados.

Palabras clave: Climatología; Lluvia; Índice de anomalías de lluvia; Sequía; Severidad climática.

\section{Introdução}

Responsável pela “entrada" de água no ciclo hidrológico, a precipitação, popularmente conhecida como "chuva”, é um dos principais elementos climáticos e está diretamente associada à disponibilidade hídrica de determinado local. Assim, a caracterização da precipitação, além de ser essencial à estimativa de um balanço hídrico, é variável fundamental no planejamento e zoneamento territorial, na gestão dos recursos hídricos, nos serviços públicos de saneamento básico e abastecimento de água, no setor elétrico e no agronegócio, dentre outros. Portanto, trata-se de uma condicionante na cadeia socioeconômica do país que deve recrutar atenção e esforços da sociedade (Bertoni \& Tucci, 2012, p.183).

Segundo a Defesa Civil Estadual (Espírito Santo, 2020), a estiagem, período de baixos quantitativos de chuvas ou mesmo de ausência de precipitação, no qual a perda de umidade do solo é superior à sua reposição, é o desastre mais frequente no Espírito Santo. Durante a crise hídrica ocorrida no sudeste do Brasil entre os anos de 2014 e 2016, considerada a pior da história do país, foram decretados 167 casos de estiagem no Estado. Neste período, além das perdas de safras inteiras e consequentes prejuízos impostos ao agronegócio (empregador de 33\% da população economicamente ativa do Espírito Santo, responsável por 30\% do PIB Estadual e principal atividade econômica em $80 \%$ dos municípios capixabas), observou-se a intensificação dos conflitos pelo uso da água na região Central Espírito-Santense, o que representa um grande desafio no campo da segurança hídrica aos sistemas regionais de governança das bacias hidrográficas (AGERH, 2018; Espírito Santo, 2020; Espírito Santo, 2021). Este cenário reveste de importância a caracterização climática de tal região, especialmente da precipitação pluviométrica.

O Rainfall Anomaly Index (RAI - Índice de Anomalia de Chuva - IAC) desenvolvido por Rooy (1965), por exemplo, além de possibilitar a caracterização das severidades positivas e negativas das anomalias das chuvas, permite a análise da distribuição e intensidade das precipitações, especialmente para as ocorrências de secas. Diversos são os trabalhos dedicados ao estabelecimento deste indicador em diferentes regiões do país. Marcuzzo e Goularte (2012), ao avaliar o IAC em Tocantins, observaram uma diminuição média da precipitação pluviométrica no período compreendido entre os anos de 1990 e 2006 e concluíram que ocorreu uma mudança nos padrões de chuva no Estado. Alves et al. (2016), ao analisarem o IAC de quatro municípios de diferentes mesorregiões do Estado de Pernambuco, verificaram que existem diferenças pluviométricas substanciais entre as regiões e que, desta forma, cada uma apresenta aptidões distintas para o desenvolvimento de culturas 
agrícolas. Maniçoba et al. (2017), ao investigarem as séries temporais de variabilidade pluviométrica de seis municípios de diferentes mesorregiões do Estado do Rio Grande do Norte, inferiram que a significativa oscilação entre os anos chuvosos e secos das séries históricas somada à elevada quantidade de anos que apresentaram IAC negativo em todos os municípios caracterizam as localidades adotadas como instáveis para a produção agrícola de sequeiro.

Neste sentido, este trabalho teve como objetivo avaliar o IAC da região central do Estado do Espírito Santo considerando a metodologia proposta por Rooy (1965) e adaptada por Freitas (2004) e Araújo et al. (2009). Sucessivamente, o IAC das estações adotadas foi comparado com os parâmetros das Zonas Naturais do Espírito Santo (Espírito Santo, 1999). Adicionalmente, visando verificar os impactos que o clima global causa sobre a distribuição pluviométrica regional, foram consideradas as eventuais influências de El Niño (EN) e La Niña (LN) sobre os valores de IAC obtidos.

\section{Metodologia}

\subsection{Caracterização climática do Estado do Espírito Santo}

O Estado do Espírito Santo localiza-se na Zona Tropical Central, caracterizando-se pela predominância de clima tropical úmido (Am), pela inexistência de estação fria definida e pela ocorrência de secas pelo período máximo de 3 meses ao ano (INCAPER, 2021). Dentre os fenômenos atmosféricos que influenciam as características climáticas do Estado, destacamse a Zona de Convergência do Atlântico Sul (ZCAS) e a Temperatura Superficial do Mar (TSM). A ZCAS é o principal sistema meteorológico com atuação no Espírito Santo. Entre os meses de outubro e abril (primavera-verão estendida), a ZCAS provoca precipitações elevadas no Centro-Oeste e Sudeste do Brasil. Eventualmente, porém, a ausência de precipitação e descaracterização deste sistema culmina em extensos períodos de seca ou mesmo na distribuição irregular das chuvas em todo território nacional (INCAPER, 2021). Já a TSM é dividida em duas fases: EN e LN. O EN ocorre graças ao aquecimento das águas superficiais e subsuperficiais do Oceano Pacífico Equatorial e pela redução dos ventos alísios na região equatorial. Por sua vez, a LN representa um fenômeno oceânico-atmosférico com dinâmica contrária ao EN, notabilizando-se pelo esfriamento anormal das águas superficiais e subsuperficiais do Oceano Pacífico Equatorial (INCAPER, 2021).

\subsection{Localização e caracterização da área de estudo}

O Espírito Santo situa-se na região Sudeste do Brasil e possui um território de 46.074,447 km² (IBGE, 2021). Segundo Espírito Santo (1999), o Estado é marcado pela diversidade de temperaturas, topografias e regimes de chuvas, possuindo 9 zonas naturais distintas. Para delimitação da região central do Espírito Santo, área na qual desenvolveu-se o presente trabalho, considerou-se a divisão das ottobacias nível 4 do Estado. Como demonstrado na Figura 1, foram adotadas 12 estações pluviométricas operadas pela Agência Nacional de Águas e Saneamento Básico (ANA, 2021) localizadas nas seguintes ottobacias: 7616 (Rio Santa Maria do Rio Doce), 7617 (ITB Rio Santa Joana), 7618 (Rio Guandu), 7711 (ITB Rio Riacho), 7712 (Rio Santa Maria da Vitória) e 7714 (Rio Jucu). Somadas, as áreas destas ottobacias perfazem 12.008,660 km², o que corresponde a 26,06\% do território do Estado. 
Figura 1: Localização do Estado do Espírito Santo, das ottobacias e estações pluviométricas.

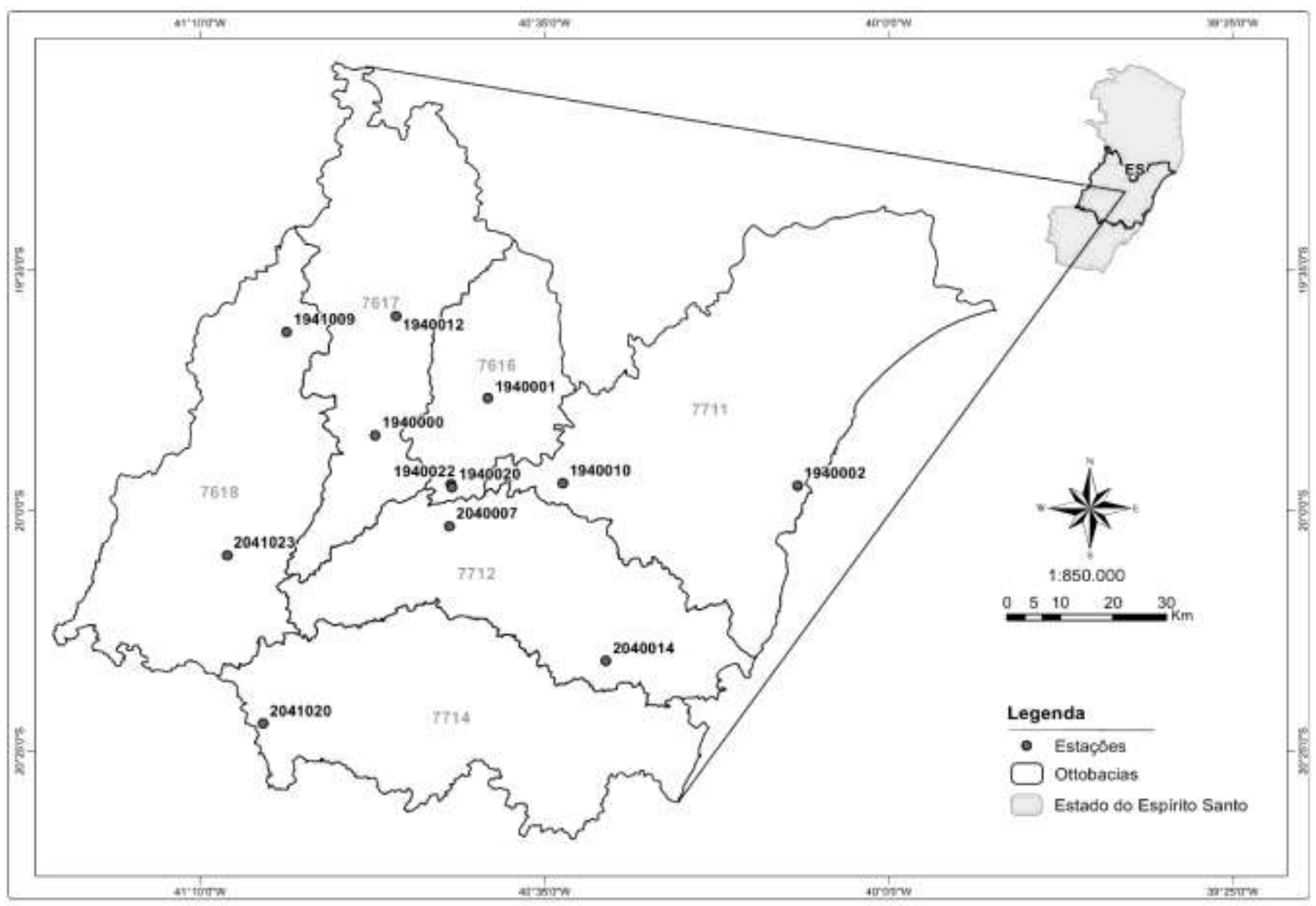

Fonte: Adaptado de Geobases (2021).

De acordo com Espírito Santo (1999), a região central do Estado possui 8 diferentes Zonas Naturais. Como se verifica na Figura 2, são predominantes as zonas quentes, acidentadas e secas (21,47\% da área de estudo); as zonas quentes, planas e chuvosas secas $(18,05 \%$ da área de estudo); as zonas frias, acidentadas e chuvosas (17,55\% da área de estudo) e as zonas amenas, acidentadas e chuvosas (14,38\% da área de estudo). As demais 04 zonas perfazem 28,55 \% da área de estudo. 
Figura 2: Classificação da área de estudo segundo as Zonas Naturais do Espírito Santo.

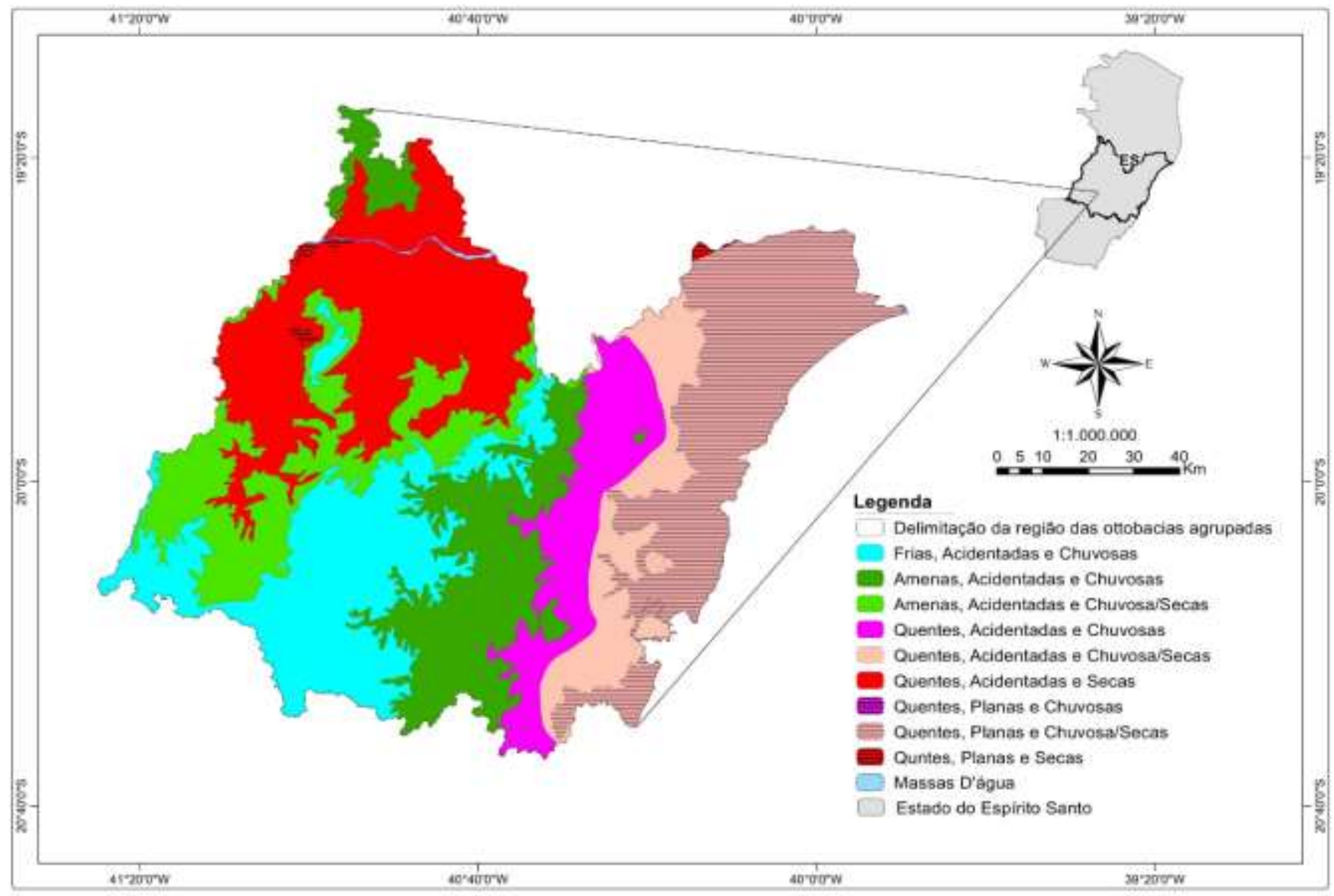

Fonte: Adaptado de Geobases (2021) e Espírito Santo (1999).

\subsection{Coleta de dados pluviométricos}

Foram utilizadas séries de precipitação total mensal, cujos dados foram extraídos do Sistema de Informações Hidrológicas (HidroWeb v3.1.0) disponível no sítio eletrônico da ANA (2021). A Tabela 1 apresenta as informações das 12 estações pluviométricas utilizadas, selecionadas em função da oferta de dados na região central do Estado do Espírito Santo:

Tabela 1: Estações climatológicas do HidroWeb utilizadas, incluindo a código de identificação, nome da estação / região, coordenadas, altitude e extensão da série.

\begin{tabular}{lcccccc}
\hline Código & Nome da Estação & Município & Lat. & Long. & Altitude (m) & $\begin{array}{c}\text { Período de } \\
\text { Observação }\end{array}$ \\
\hline 1940002 & Santa Cruz - Litoral & Aracruz & $-19,958$ & $-40,154$ & 5 & $1990-2017$ \\
1940010 & Valsugana Velha - Montante & Santa Teresa & $-19,953$ & $-40,553$ & 180 & $1991-2017$ \\
1940022 & Jacupemba & Aracruz & $-19,955$ & $-40,742$ & 750 & $1988-2017$ \\
2040014 & Duas Bocas (Dnos) & Cariacica & $-20,261$ & $-40,479$ & 200 & $1990-2015$ \\
2041023 & Afonso Claúdio - Montante & Afonso Cláudio & $-20,079$ & $-41,121$ & 300 & $1991-2017$ \\
1941009 & Ibituba & Baixo Guandú & $-19,691$ & $-41,020$ & 160 & $1988-2017$ \\
1940001 & São João De Petrópolis & Santa Teresa & $-19,805$ & $-40,679$ & 149 & $1990-2017$ \\
1940012 & Itaimbé & Itaguaçu & $-19,664$ & $-40,835$ & 70 & $1988-2017$ \\
2040007 & Santa Maria Do Jetibá & Santa Maria De Jetibá & $-20,028$ & $-40,740$ & 710 & $1990-2017$ \\
2041020 & Arace (Fazenda Modelo) & Domingos Martins & $-20,366$ & $-41,061$ & 1075 & $1990-2017$ \\
1940000 & Itarana & Itarana & $-19,874$ & $-40,874$ & 165 & $1988-2017$ \\
1940020 & Caldeirão & Santa Teresa & $-19,955$ & $-40,741$ & 750 & $1990-2016$ \\
\hline
\end{tabular}

Fonte: Adaptado de ANA (2021). 


\subsection{Preenchimento de falhas nas séries históricas}

Depois de extraídos do portal HidroWeb, os dados foram tabulados no software Microsoft Excel 2016. Verificou-se que as estações 1940000, 1941009, 1940010, 1940012 e 2041020 dispunham de séries pluviométricas completas. Entretanto, as estações 1940002, 1940022, 1940001, 1940020, 2041023, 2040007 e 2040014 apresentavam falhas na série histórica entre os anos de 1994 e 2016. Por conseguinte, antes de realizar o cálculo do Índice de Anomalia de Chuva, foi necessário preencher estas falhas adotando-se o método de Ponderação Regional (Bertoni \& Tucci, 2012). Para tanto, foram selecionados 03 postos pluviométricos circunvizinhos a cada uma das estações que apresentavam falhas, admitindo-se postos que dispusessem de séries pluviométricas mínimas de 15 anos e apresentassem a maior similaridade edafoclimática possível com a estação falha. Na Tabela 2 estão detalhadas as estações com meses falhos e respectivos postos selecionados para aplicação do método.

Tabela 2: Estações pluviométricas com meses falhos e respectivos postos selecionados para aplicação do método de ponderação regional.

\begin{tabular}{ccc}
\hline $\begin{array}{c}\text { Estações } \\
\text { com falhas }\end{array}$ & Meses sem dados disponíveis & $\begin{array}{c}\text { Estações selecionadas para } \\
\text { preenchimento das falhas }\end{array}$ \\
\hline 1940002 & Janeiro-2009 & $1940005,1940022,1940010$ \\
1940022 & Março-1993; Fevereiro-1995 & $1940005,1940022,1940010$ \\
2040014 & Agosto-2014 & $1940002,2040008,2041020$ \\
2041023 & Janeiro-2010; Setembro-2010; Janeiro-2015; Outubro-2016 & $2040007,2040008,2041020$ \\
1940001 & Março-1994; Janeiro-2001; Setembro-2001; Novembro-2001 & $1940000,1940012,1941009$ \\
2040007 & Janeiro-1994; Fevereiro-1994; Março-1994; Abril-1994; Setembro-2006 & $1940000,1940010,2040008$ \\
1940020 & Abril-2002; Maio-2002; Junho-2002; Março-2005; Abril-2005; Setembro- & $1940000,2040008,1940010$ \\
\hline
\end{tabular}

Fonte: Adaptado de ANA (2021).

O método de ponderação regional requer a aplicação da Equação 1 proposta por Bertoni e Tucci (2012):

$y=\frac{1}{N} *\left(\frac{X_{1}}{X_{m 1}}+\frac{X_{2}}{X_{m 2}}+\frac{X_{a}}{X_{m a}}\right) * y_{m}$ (Equação 1)

Onde:

$\mathrm{y}=$ é a precipitação do posto a ser estimada;

$\mathrm{N}$ = é o número de estações utilizadas no preenchimento da falha;

$\mathrm{X}_{1}, \mathrm{X}_{2}$ e $\mathrm{X}_{3}=$ são as precipitações correspondentes ao mês que se deseja preencher, observadas em três estações vizinhas;

$\mathrm{X}_{\mathrm{m} 1}, \mathrm{X}_{\mathrm{m} 2}$ e $\mathrm{X}_{\mathrm{m} 3}=$ são as precipitações médias mensais nas três estações circunvizinhas;

$\mathrm{y}_{\mathrm{m}}=$ é a precipitação média mensal do posto $\mathrm{y}$.

\section{5 Índice de Anomalia de Chuvas (IAC)}

Para a classificação dos períodos secos e úmidos foi utilizado o IAC (Índice de Anomalia de Chuvas) proposto por Rooy (1965) e posteriormente adaptado por Freitas (2004), expresso pelas equações 2 e 3:

$I A C=-3\left[\frac{(N-\bar{N})}{(\bar{X}-\bar{N})}\right]$

(Equação 2)

para anomalias positivas;

$I A C=3\left[\frac{(N-\bar{N})}{(\bar{X}-\bar{N})}\right]$

(Equação 3) 
para anomalias negativas, onde:

$\mathrm{N}=$ precipitação mensal atual (mm.mês $\left.{ }^{-1}\right)$;

$\mathrm{N}=$ precipitação média mensal da série histórica $\left(\mathrm{mm} \cdot \mathrm{mês}^{-1}\right)$;

$M=$ média das dez maiores precipitações mensais da série histórica (mm.mês ${ }^{-1}$ );

$\mathrm{X}=$ média das dez menores precipitações mensais da série histórica (mm.mês $\left.{ }^{-1}\right)$.

A partir dos resultados obtidos, classificou-se o regime de chuvas de acordo com a metodologia do IAC adaptada por Araújo et al. (2009) detalhada na Tabela 3.

Tabela 3: Classificação da precipitação segundo o IAC.

\begin{tabular}{cc}
\hline Índice de Anomalia de Chuva (IAC) & Classificação da Precipitação \\
\hline Maior que 4 & Extremamente Chuvoso (EC) \\
Entre 2 e 4 & Muito Chuvoso (MC) \\
Entre 0 e 2 & Chuvoso (C) \\
0 & Nem Chuvoso Nem Seco \\
Entre 0 e -2 & Seco (S) \\
Entre -2 e -4 & Muito Seco (MS) \\
Menor que -4 & Extremamente Seco (ES) \\
\hline
\end{tabular}

Fonte: Adaptado de Araújo et al. (2009).

\section{Resultados e Discussão}

\subsection{Caracterização da precipitação}

A área de estudo exibe relevante amplitude pluviométrica. Deu-se na estação 1940010 a maior precipitação média mensal no período adotado (novembro - 285,12 mm). Este posto está localizado em região chuvosa onde o mês de novembro é tipicamente úmido conforme a classificação das Zonas Naturais do Espírito Santo (Espírito Santo, 1999). A menor precipitação média mensal ocorreu na estação 1941009 em julho (8,77 mm), mês caracteristicamente seco na Zona Natural em que tal posto está instalado (Espírito Santo, 1999). Excluindo-se a estação 1940022 (na qual a menor média mensal aconteceu no mês de setembro), nos demais postos as menores médias mensais ocorreram nos meses de julho e agosto. Em todas as estações as maiores médias mensais foram observadas nos meses de dezembro e janeiro. A Tabela 4 exibe os valores médios mensais e totais anuais de precipitação das estações. Levando-se em conta os valores médios mensais de precipitação de cada posto, determinou-se a precipitação média mensal da área de estudo no período observado conforme demonstra a Figura 3. Janeiro, março, novembro e dezembro apresentaram médias mensais superiores à média anual enquanto fevereiro, abril, maio, junho, julho, agosto, setembro e outubro apresentaram médias mensais inferiores à média anual. 
Tabela 4: Precipitação média mensal da área de estudo.

\begin{tabular}{|c|c|c|c|c|c|c|c|c|c|c|c|c|}
\hline \multirow[b]{2}{*}{ Mês } & \multicolumn{12}{|c|}{ Estações pluviométricas } \\
\hline & 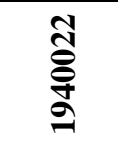 & 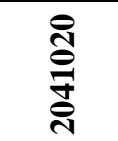 & 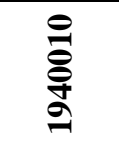 & 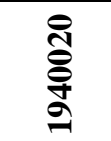 & 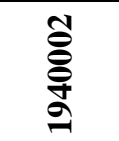 & 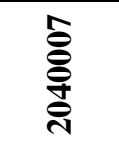 & 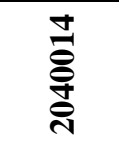 & 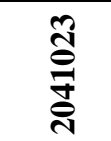 & 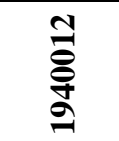 & $\frac{\hat{\sigma}}{\sigma}$ & $\begin{array}{l}\text { ఫे } \\
\text { ఫે }\end{array}$ & 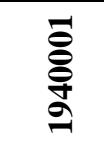 \\
\hline Jan & 117,04 & 186,18 & 211,47 & 157,11 & 106,91 & 143,13 & 142,96 & 205,50 & 134,52 & 104,54 & 142,97 & 146,24 \\
\hline Fev & & ,09 & 27 & & & 22 & & 92,09 & & &, 46 & 82,94 \\
\hline Mar & 20 & 166,01 & 02 & 119,93 & 125,61 & 154,26 & 76 & 137,52 & & 101,12 & 5,88 & 127,33 \\
\hline Abr & 85,11 & 91,43 & 128,89 & 68,13 & 98,18 & 82,11 & 112,45 & 65,76 & 65,08 & 45,03 & 58,27 & 58,77 \\
\hline Mai & & 43,87 & 77,09 & 36,63 & 82,15 & 49,63 & 59,09 & 39,10 & 37,09 & 32,14 & 40,14 & 32,04 \\
\hline Jun & & & 39 & 24,52 & 67,24 & & 07 & 8 & & 13,75 & 19,60 & 20,28 \\
\hline Jul & 45,01 & 20,42 & 101,97 & 24,81 & 74,09 & 28,08 & 53,15 & 13,04 & 13,50 & 8,77 & 11,76 & 17,55 \\
\hline Ago & 45,64 & 23,26 & 107,01 & 25,95 & 52,91 & 33,94 & 59,63 & 14,28 & 17,75 & 10,38 & 14,74 & 16,96 \\
\hline Set & & & 109,97 & 34,90 & 55,23 & 45,95 & & 35,67 & 29 , & 26,01 & 29,96 & 29,29 \\
\hline Out & & & & & 93,66 & 97,64 & & & & & 86,78 & 86,11 \\
\hline Nov & 85 & 00 & $2 \varepsilon$ & 205 & & 196,13 & & 194,48 & & 173,79 & 195,56 & 174,50 \\
\hline Dez & 194,68 & 277,10 & 273,37 & 241,55 & 157,66 & 238,70 & 250,79 & 246,82 & 229,78 & 191,23 & 234,92 & 205,15 \\
\hline Total & 1148,8 & 1316,1 & 1843,7 & 1112,4 & 1171,1 & 1196,2 & 1449,7 & 1146,2 & 1038,6 & 849,8 & 1052,0 & 997,2 \\
\hline
\end{tabular}

Fonte: Autores (2021).

Figura 3: Precipitação média mensal $(\mathrm{mm})$ na área de estudo.

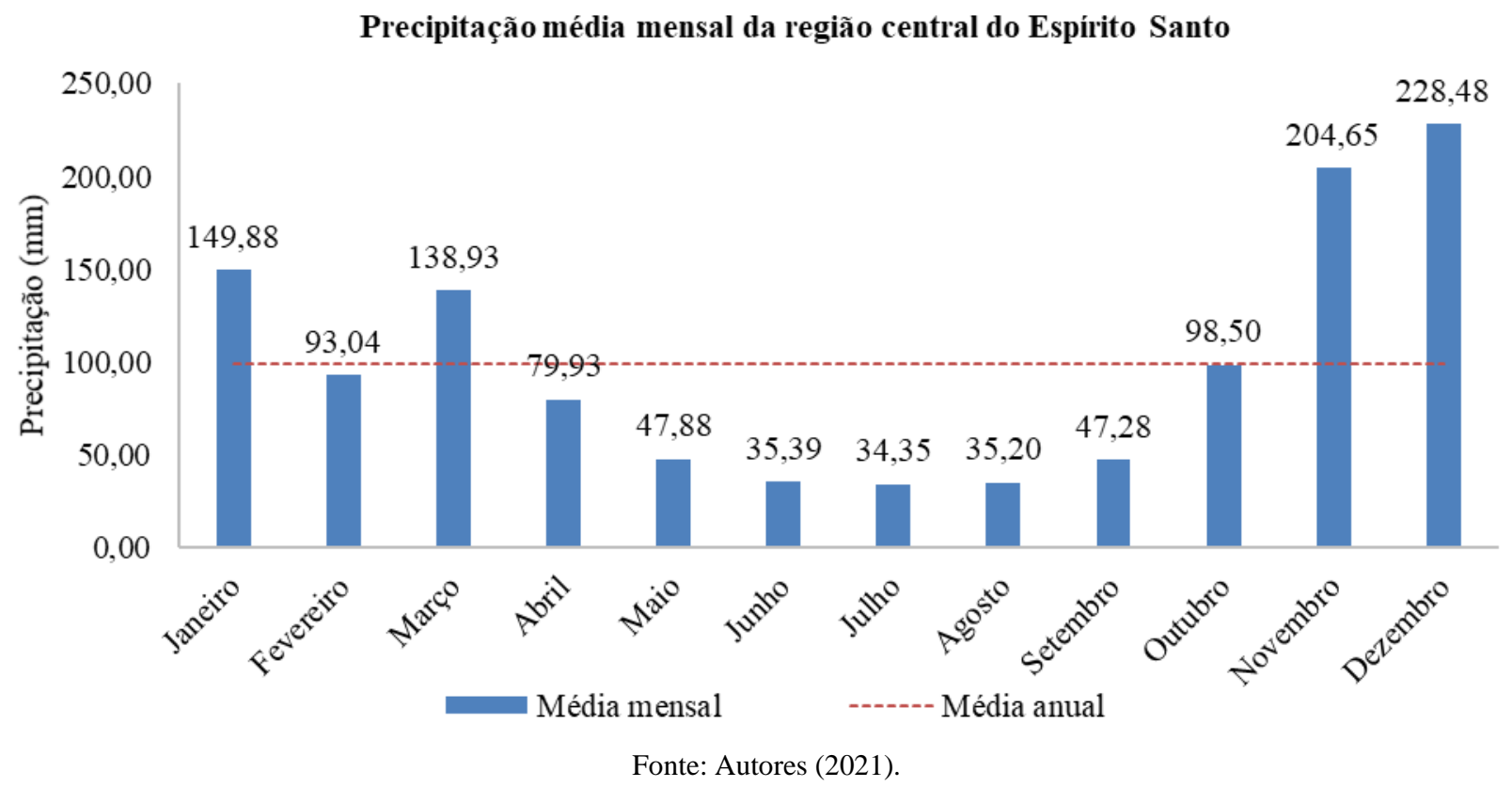

3.2 Avaliação do Índice de Anomalia de Chuvas (IAC)

Como pode ser visualizado na Figura 4, as estações pluviométricas selecionadas para o presente trabalho são caracterizadas por sequências de anos com ocorrência de anomalias negativas e sequências de anos com ocorrência de anomalias positivas. Consequentemente, é plausível inferir que o comportamento pluviométrico na área de estudo é marcado pela linearidade entre anos secos e chuvosos, diferindo do que examinaram Maniçoba et al. (2017). Esta constatação é particularmente importante tendo em vista as implicações em setores importantes da cadeia econômica como o setor elétrico e o agronegócio, por exemplo, presentes na região em estudo. Anos seguidamente secos, além de comprometer a estabilidade fluviométrica necessária à geração de eletricidade por usinas hidrelétricas, como observado por Vilar et al. (2020) e Silva et al. (2020), reduzem a produtividade agrícola de áreas que não adotam sistemas de irrigação suplementar a exemplo do que 
demonstraram Santos et al. (2011). Por outro lado, anos seguidamente chuvosos também contribuem para a maior incidência de doenças nas culturas de interesse agronômico, como demonstraram Ricce et al. (2016).

Figura 4: IAC por estação pluviométrica.
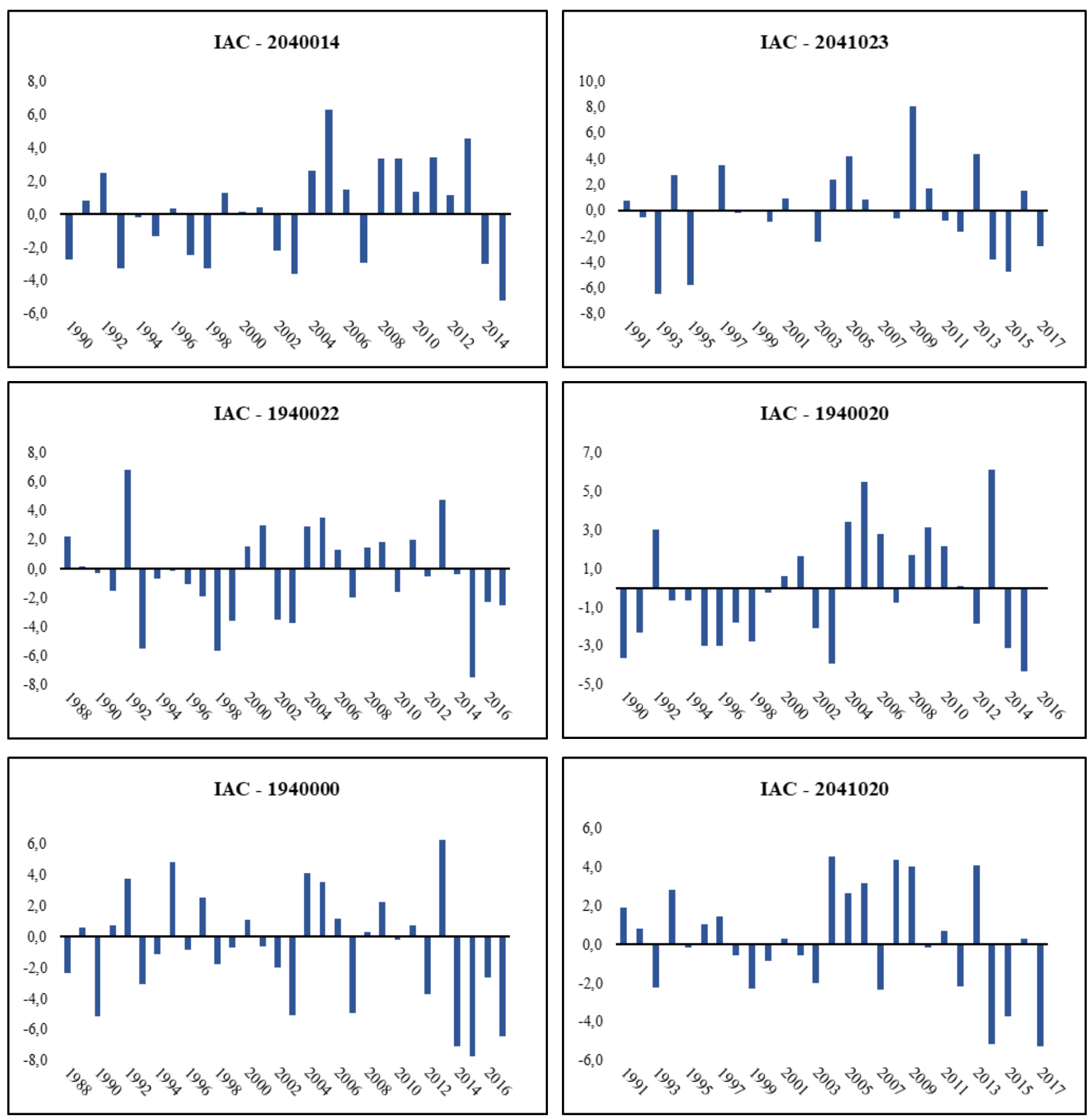

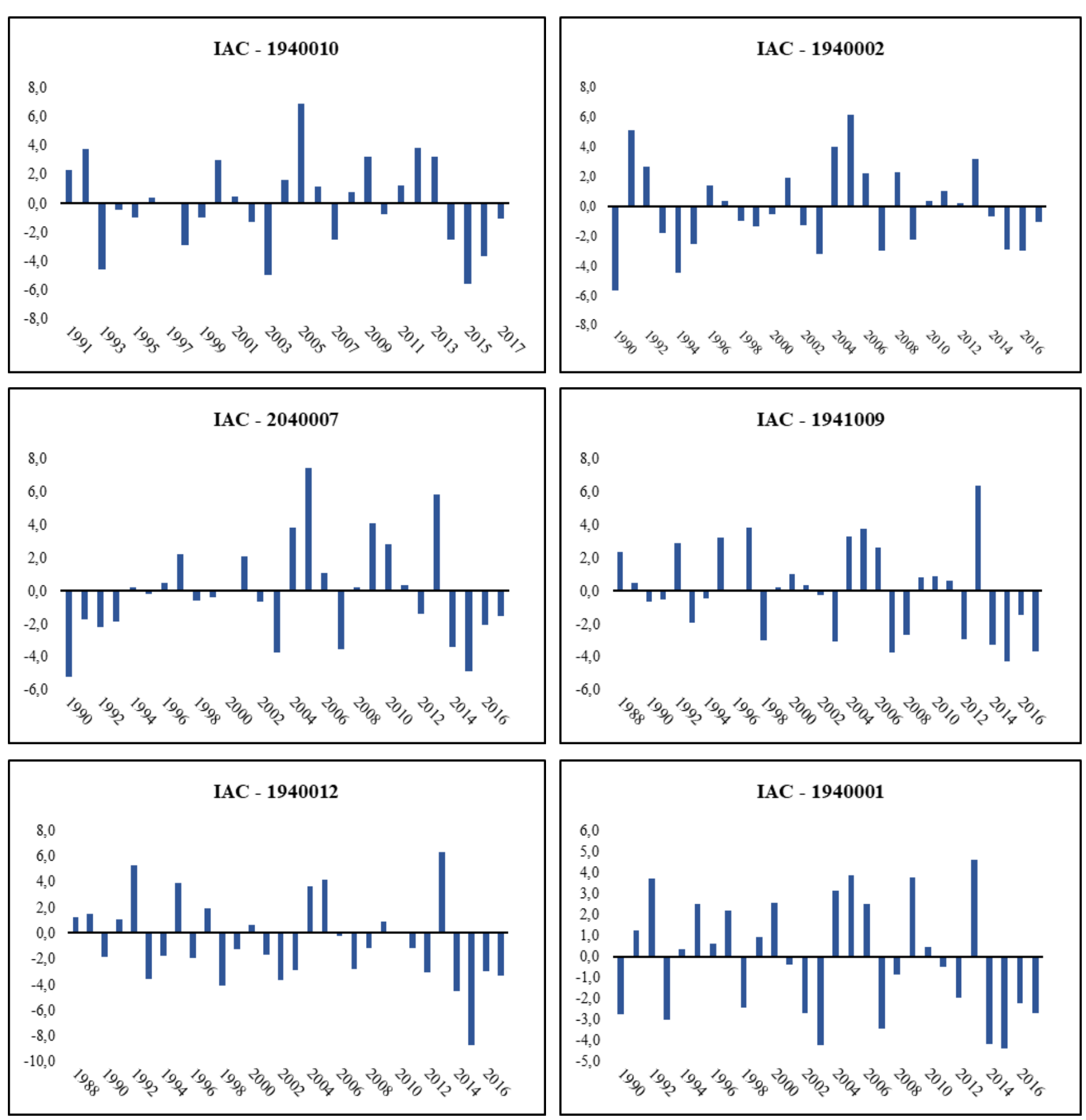

Fonte: Autores (2021).

A Figura 5 demonstra a variação do IAC médio anual entre os anos de 1991 e 2015 (período no qual todas as estações pluviométricas adotadas possuem dados de precipitação disponíveis) na região central do Estado do Espírito Santo. A quantidade de anos com anomalias positivas (15) é superior ao número de anos com anomalias negativas (10). Os anos de 2005 e 2013 apresentam-se como únicos extremamente chuvosos $(4,8)$ enquanto o ano de 2015 foi o único extremamente seco (4,9). Observa-se uma inflexão em 2003, a partir de quando ocorreram 4 anos muito chuvosos (2004, 2005, 2009 e 2013) e 4 anos muito secos (2003, 2007, 2014 e 2015). Entre 1991 e 2002 foram observados 2 anos muito secos (1993 e 1998$)$ e 1 muito chuvoso (1992). Desta forma, este ponto de inflexão marca o aumento na frequência de eventos severos na área de estudo. 
Figura 5: IAC médio anual na área de estudo entre os anos de 1991 e 2015.

IAC médio anual da região central do Espírito Santo (1991 - 2015)

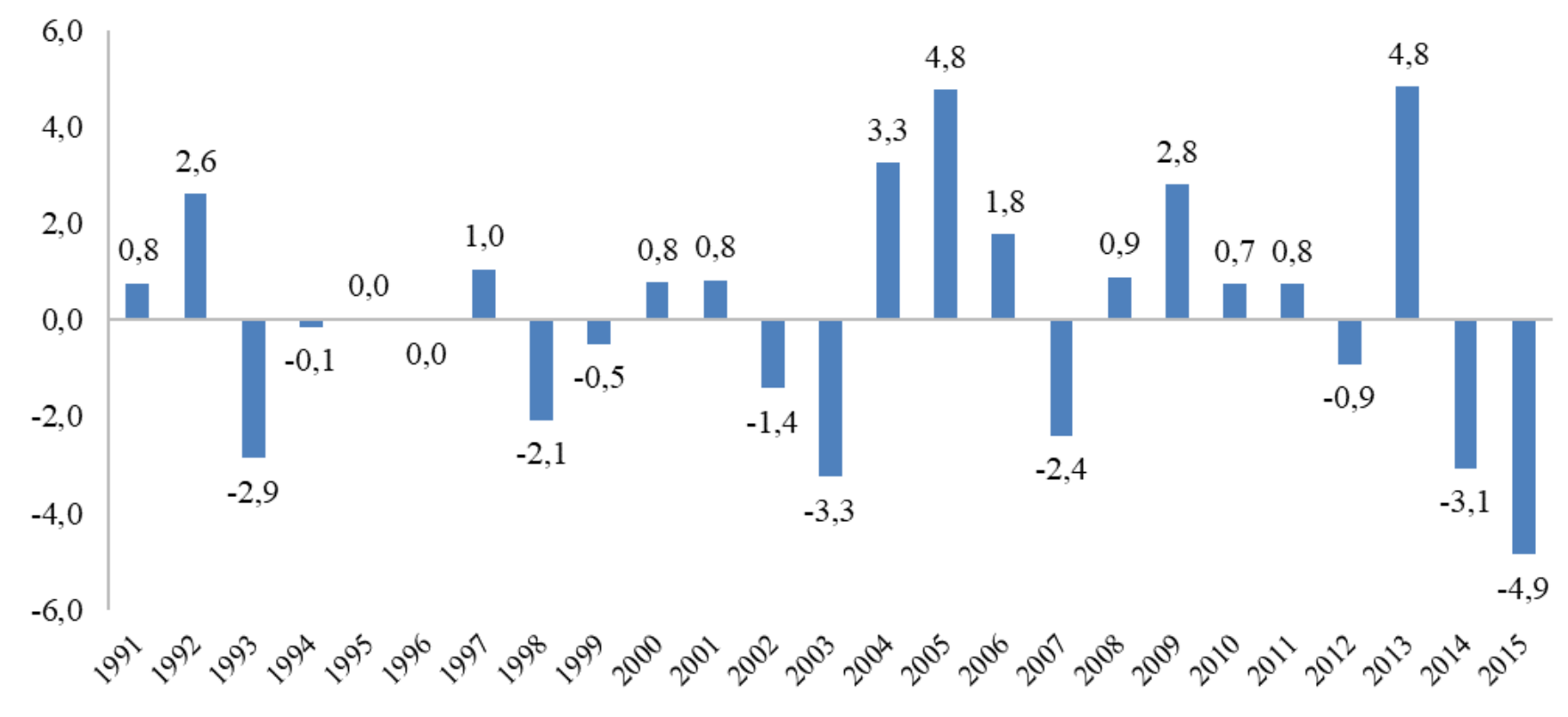

Fonte: Autores (2021).

Como pode ser verificado na Figura 06, as estações pluviométricas 1940012, 2041023, 1940002, 1940010, 1940020 e 2040007 apresentaram mais anos com anomalias negativas de precipitação, corroborando assim as investigações de Marcuzzo e Goularte (2012) e Gross e Cassol (2015). Vale destacar que os três últimos postos supramencionados estão inseridos em regiões chuvosas de acordo com a classificação das Zonas Naturais do Espírito Santo. Já nas estações 2040014 , 1941009 e 1940000 ocorreram mais anos com anomalias positivas de chuvas. Destes, os dois últimos postos citados estão localizados em regiões secas conforme o Zoneamento Natural do Estado. Por fim, nas estações 2041020, 1940022 e 1940001 a quantidade de anos com anomalias positivas e negativas é a mesma. É imperioso frisar que estes postos operam em regiões distintas quanto à pluviosidade segundo a classificação das Zonas Naturais do Espírito Santo. 
Figura 6: Indicação de postos pluviométricos de acordo com a quantidade de anos secos e chuvosos.

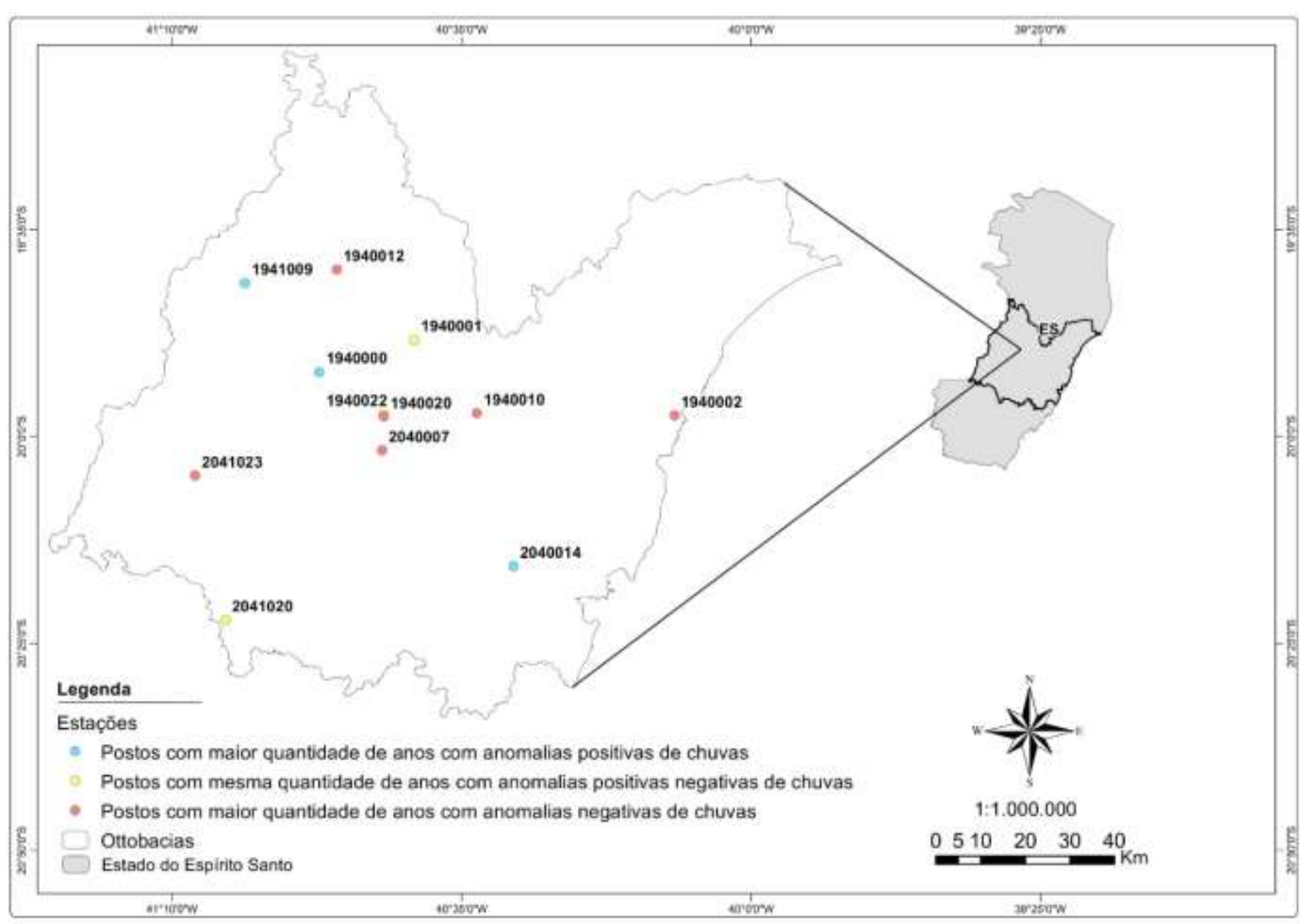

Fonte: Autores (2021).

A maior severidade negativa (-7,1) do Índice de Anomalia de Chuva (IAC) foi encontrada na estação 1940012 em 2015, ano no qual os postos 1940010, 1940020, 2040014, 1941009, 1940000, 1940022 e 1940001 também apresentaram suas maiores severidades negativas. Em janeiro de 2015 todas as estações pluviométricas objeto deste estudo registraram chuvas abaixo da média histórica, sendo que as estações 1941009 e 1940000 não registraram precipitações no mês em questão. Considerando-se dados divulgados pela National Oceanic and Atmospheric Administration (NOAA, 2021), é provável que eventos de EN ocorridos em 2015 influenciaram tais severidades negativas em conformidade com o constatado por Silva et al. (2020). Observou-se na estação 2041023 no ano de 2009 a maior extremidade positiva $(8,0)$ do IAC. Possivelmente este resultado está associado aos eventos de LN ocorridos no ano de 2009 de acordo com dados da NOAA (2021), corroborando o trabalho de Silva et al. (2020). É salutar mencionar que o ano de 2005 (no qual verificou-se ocorrências de EN) apresentou os maiores valores positivos para as estações 1940010, 1940020, 1940002, 2040007 e 2040014. Diante das máximas positivas e negativas assinaladas, é pertinente afirmar que a região central do Estado do Espírito Santo é marcada pela elevada amplitude do IAC a exemplo do que Marcuzzo e Goularte (2012) e Gross e Cassol (2015) observaram.

Em 91,6\% das estações, os maiores valores positivos se concentraram nos últimos 14 anos da série histórica enquanto os maiores valores negativos se detiveram nos 4 anos finais da série histórica em $75 \%$ dos postos. Estes resultados apontam para o aumento da frequência de eventos severos na região central do Estado do Espírito Santo. 
Excetuando-se as estações 1940020, 2041023, 02040014, 2041020, todos os postos pluviométricos apresentaram anomalias negativas nos últimos 4 anos do período avaliado. Este período é notabilizado pela crise hídrica no sudeste do Brasil, considerada a pior da história do país até então (ANA, 2019). É provável que exista correlação desta sequência de anos secos com episódio da EN em 2015 e 2016, sendo que em 2016 adveio EN forte (NOAA, 2021), consoante observou Silva et al. (2020).

Em 9 estações a quantidade de anos chuvosos é maior que a quantidade de anos secos nos últimos 15 anos da série histórica avaliada. No mesmo período, contudo, nas estações 1940012, 1941009 e 1940001 houve diminuição no número de anos chuvosos e aumento no número de anos secos, inversão análoga à verificada por Marcuzzo \& Goularte (2012).

\section{Conclusão}

Conclui-se, a partir dos valores médios mensais de precipitação e das maiores severidades positivas e negativas do IAC de cada posto, que a área de estudo caracteriza-se pela elevada amplitude de variação pluviométrica. O ano 2015, marcado por episódios de EN e no qual aconteceu a maior severidade negativa, foi notavelmente crítico porquanto no mês de janeiro todas as estações registraram chuvas inferiores à média histórica, sendo que os postos 1941009 e 1940000 sequer registraram precipitações. Já em 2009, ano em que ocorreram eventos de LN, observou-se na estação 2041023 a maior extremidade positiva $(8,0)$.

Os postos 1940010, 1940020 e 2040007 apresentaram mais anos com anomalias negativas de precipitação a despeito de estarem inseridos em regiões definidas como "chuvosas". Nas estações 1941009 e 1940000, localizadas em regiões definidas como "secas", observaram-se mais anos com anomalias positivas. Nos últimos 15 anos da série histórica notou-se diminuição no número de anos chuvosos e aumento no número de anos secos nos postos 1940012, 1941009 e 1940001. Estas aparentes contradições e alterações nos padrões das chuvas, respectivamente, evidenciam a necessidade da realização de mais pesquisas climatológicas na região, com ênfase no comportamento da precipitação pluviométrica, visando o aperfeiçoamento do Zoneamento Natural do Estado do Espírito Santo.

O IAC médio anual da área de estudo entre os anos de 1991 e 2015 apresentou uma inflexão em 2003, a partir de quando ocorreram 4 anos muito chuvosos, 4 anos muito secos, 2 anos extremamente chuvosos e 1 ano extremamente seco. A título de comparação, entre os anos de 1991 e 2002, além de não se observar anos extremamente secos ou extremamente chuvosos, verificou-se apenas 1 ano muito seco e 2 anos muito chuvosos. Assim, este ponto de inflexão aponta para o aumento da ocorrência de eventos severos na área de estudo, o que deve demandar esforços preventivos do poder público tendo em vista os possíveis efeitos danosos na cadeia socioeconômica da região bem como os múltiplos desastres socioambientais potencialmente associados, quais sejam, estiagem, alagamentos e instabilidade geotécnica, dentre outros.

\section{Referências}

AGERH - Agência Estadual De Recursos Hídricos. Diagnóstico e Prognóstico das Condições de Uso da Água na Bacia Hidrográfico do Rio Novo. 2018. Disponível em: <agerh.es.gov.br>

ANA - Agência Nacional Das Águas e Saneamento Básico. Conjuntura Recursos Hídricos Brasil. $2019 . \quad<$ http:// http://conjuntura.ana.gov.br/static/media/conjuntura-completo.bb39ac07.pdf />.

ANA - Agência Nacional Das Águas e Saneamento Básico. HidroWeb. 2021. <http:// www.snirh.gov.br/hidroweb/serieshistoricas

Alves, J. O., Pereira, P. C., Queiroz, M. G., Silva, T. G. F., Ferreira, J. M. S. \& Nascimento Jr, G. Índice de anomalia de chuva para diferentes mesorregiões do Estado de Pernambuco. Manhuaçu: Pensar Acadêmico, 14(1), 37-47, 2016.

Araújo, L. E., Moraes Neto, J. M. \& Salviano de Sousa, F.A. Classificação da precipitação anual e da quadra chuvosa da bacia do rio Paraíba utilizando Índice de Anomalia de Chuva (IAC). Taubaté: Ambiente \& Água - An Interdisciplinary Journal of Applied Science, 4(3), 93-110, 2009.

Bertoni, J. C. \& Tucci, C. E. M. Precipitação. In.: Tucci, C. E. M. Hidrologia: ciência e aplicação, (4a ed.), Ed. Universidade/UFRGS: ABRH, 2012.943 p. 
Research, Society and Development, v. 10, n. 12, e94101219990, 2021

(CC BY 4.0) | ISSN 2525-3409 | DOI: http://dx.doi.org/10.33448/rsd-v10i12.19990

Espírito Santo. Secretaria de Estado do Planejamento - SEPLAN. Zonas Naturais do Espírito Santo: uma regionalização do Estado, das microrregiões e dos municípios. Vitória, 1999. < http://www.ijsn.es.gov.br/ConteudoDigital/20121211_es01655_zonasnaturaisdoespiritosanto.pdf>.

Espírito Santo. Secretaria da Segurança Pública e Defesa Social. Plano Estadual de Proteção de Defesa Civil. Vitória, 2020. https://defesacivil.es.gov.br/Media/defesacivil/Acesso\%20R\%C3\%A1pido/PEPDEC\%20-\%20SITE.pdf〉.

Espírito Santo. Agronegócio. 2021. <https://www.es.gov.br/agronegocio>.

Freitas, M. A. S. Um sistema de suporte a decisão para o monitoramento de secas meteorológicas em regiões Semiáridas. Fortaleza: Revista Tecnologia, 19(1), 84-95, 2004.

GEOBASES. < https://ide.geobases.es.gov.br/layers/geonode:ottobacias_n_4>.

Gross, J. A. \& Cassol, R. Índice de anomalia de chuvas do Estado do Rio Grande do Sul. Guarapuava: Ambiência, 11(3), 529-543, 2015.

IBGE - Instituto Brasileiro De Geografia E Estatística. Informações por Cidades e Estados. < https://www.ibge.gov.br/cidades-e-estados/es/> .

INCAPER - Instituto Capixaba De Pesquisa, Assistência Técnica E Extensão Rural. Meteorologia: Estações do ano. < https://incaper.es.gov.br/>.

Maniçoba, R. M., Sobrinho, J. E., Guimarães, I. T., Cavalcante Junior, E. G., Silva, T. T. F. \& Zonta, J. H. Índice de anomalias de chuva para diferentes mesorregiões do Estado do Rio Grande do Norte. UFPE: Revista Brasileira de Geografia Física, 10(4), 1110-1119, 2017.

Marcuzzo, F. F. N. \& Goularte, E. R. P. Índice de anomalia de chuvas do Estado do Tocantins. UFG, Revista Geoambiente On-line, 19, 55-71, 2012.

NOAA - National Oceanic and Atmospheric Administration. Climate Prediction Center. 〈http://www.cpc.ncep.noaa.gov/〉.

Ricce, W. S., Padrão, G. A., Trabaquini, K., Alves, J. G. C. \& Reiter, J. M. W. Estimativas de perdas na agricultura por chuvas excessivas no Alto Vale do Rio Itajaí em 2015. Florianópolis: Agropecuária Catarinense, 29(2), 42-45, 2016.

Rooy, M. P. Van. A rainfall anomaly index independent of time and space. Notos. 14, 43-48, 1965.

Santos, R. S., Costa, L. C., Sediyama, G. C., Leal, B. G., Oliveira, R. A. \& Justino, F. B. Avaliação da relação seca/produtividade agrícola em cenário de mudanças climáticas. Revista Brasileira de Meteorologia, 26(2), 313 - 321, 2011.

Silva, F. F., Santos, F. A. \& Santos, J. M. Índice de anomalia de chuva (IAC) aplicado ao estudo das precipitações no município de Caridade, Ceará, Brasil. Revista Brasileira de Climatologia, 16(27), 426-442, 2020.

Vilar, R. A., Correia, M. F., Nóbrega, R. S., Aragão, M. R. S., Barbieri, L. F. P. \& Moura Filho, M. G. Avaliação do Impacto de Secas Severas no Nordeste Brasileiro na Geração de Energia Elétrica Através do Modelo Newave: Projeção das Energias Afluentes e Armazenadas. Revista Brasileira de Meteorologia, 35(1), 89-98, 2020. 